\title{
Pneumatocele formation in a patient with Proteus mirabilis pneumonia
}

\author{
Joseph Lysy, Arie Werczberger, Mordecai Globus and Israel Chowers
}

\author{
Department of Internal Medicine, Bikur Cholim Hospital affiliated with the Hebrew University-Hadassah Medical \\ School Jerusalem, Israel.
}

\begin{abstract}
Summary: A rare case of pulmonary pneumatoceles complicating the course of Proteus pneumonia in an adult is described. The pneumatoceles which appeared early in the course of the pneumonia resolved completely without complications. A brief review of the literature regarding formation of cavities in Proteus pneumonia is given.
\end{abstract}

\section{Introduction}

Pneumonias caused by various species of Proteus occur with increasing frequency especially in debilitated and immunosuppressed persons, and are usually secondary to aspiration of these organisms (Valdivieso, 1977).

The radiographic pattern of this disease includes dense lobar consolidation, usually of the lower lobe, cavitation, pleural effusion and atelectasis (Tillostone $\&$ Lerner, 1966a). To the best of our knowledge, large pulmonary pneumatoceles have not previously been described.

\section{Case report}

A 47 year old woman was admitted with a two-day history of cough, high fever, dyspnoea and pleuritic pain. Seventeen years previously she had a cerebrovascular accident after which she remained hemiplegic on the left side. In spite of her motor problem she was completely healthy with good rehabilitation and good functional capacity. She had smoked two packs of cigarettes per day for the past 17 years. On examination she was in respiratory distress, with respiratory rate of 60 beats $/ \mathrm{min}$ and temperature $40^{\circ} \mathrm{C}$. There were decreased breathing sounds over the base of the left lung and crepitant rales over both bases. Chest X-ray on admission revealed consolidation of the left lower lower lobe with a radiolucent area (Figure 1). A blood

J. Lysy, M.D.; A. Werczberger, M.D.; M. Globus, M.D.; I. Chowers, M.D.

Correspondence: Dr Joseph Lysy, Department of Internal Medicine, Bikur Cholim Hospital, 2-5 Strauss Street, P.O. Box 492, Jerusalem, Israel.

Accepted: 28 March 1984 culture was obtained and treatment with intravenous crystalline penicilline 6 million $\mathrm{U} / \mathrm{d}$ and tobramycin $5 \mathrm{mg} / \mathrm{kg} / \mathrm{d}$ was started. Another X-ray done a few hours later showed progression of the radiolucent area to a definite pneumatocele (Figure 2). Flexible bronchoscopy showed no evidence of obstruction. Subsequently Proteus mirabilis sensitive to tobramycin grew from blood and sputum cultures. Meanwhile the patient was improving clinically but the pneumatocele continued to progress and other massive radiolucent areas appeared in the left lung with intracavitary fluid level and concomitant deviation of the mediastinum to the right (Figure 3).

The patient became afebrile on the 16th day of hospitalization and multiple pneumatoceles were still

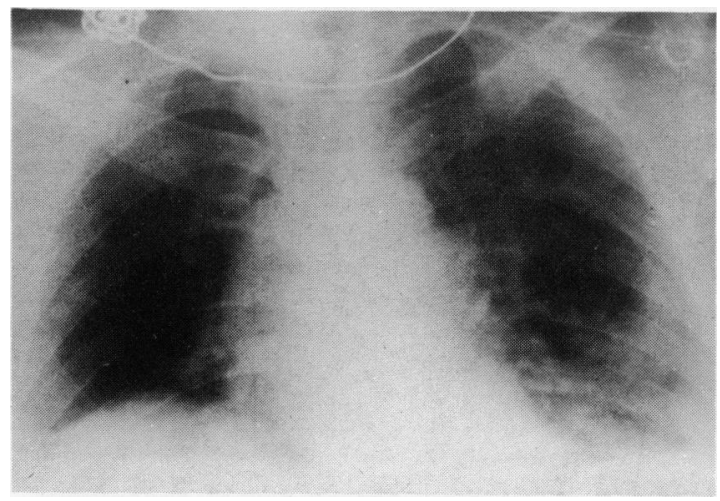

Figure 1 Admission chest X-ray film demonstrates consolidation of the left lower lobe with small pneumatocele.

(C) The Fellowship of Postgraduate Medicine, 1985 


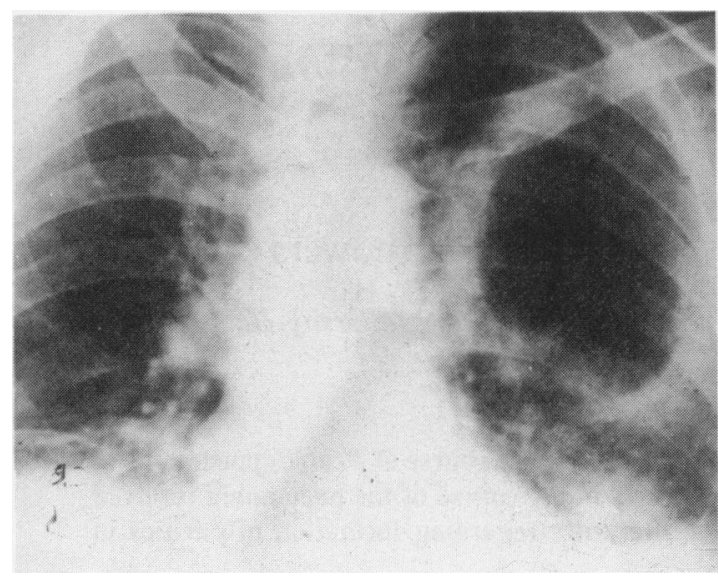

Figure 2 Chest X-ray film few hours after admission showing progression of the pneumatocele.

present on the 21st day when she was discharged (Figure 4). Complete resolution of the pneumatoceles was noted 111 days after discharge.

\section{Discussion}

Pneumatoceles (or bullae) are air-filled thin walled spaces within the lung, caused by destruction of alveolar tissue, or by one-way valve type obstruction. Fraser and Pare (1979) define pneumatocele as an aircontaining space equivalent to at least one third of the lung volume. Pneumatoceles are common complications of staphyloccocal pneumonia, particularly in

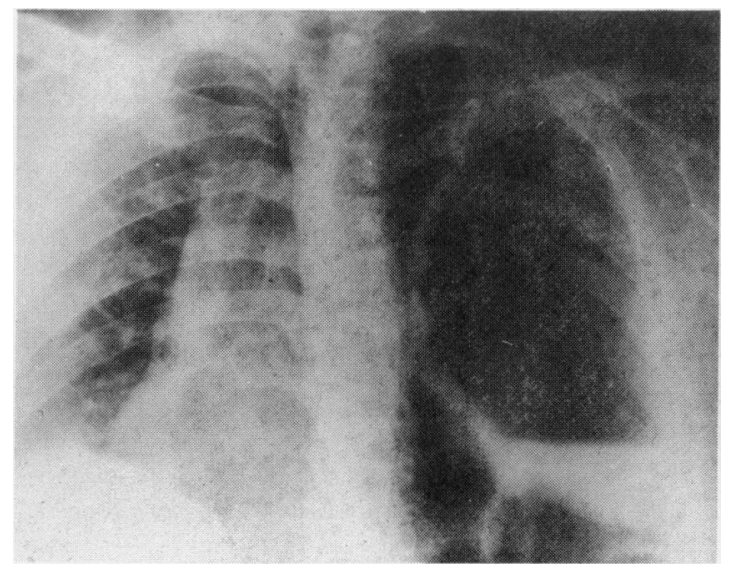

Figure 3 Chest X-ray film on day 12 demonstrates multiple pneumatoceles on the left lung with a fluid level in the largest cavity; deviation of the mediastinum to the right is noted. infants and children, but have also been described in other bacterial, tubercular, viral, parasitic and fungal pneumonias (Boisset, 1972; Luddy, 1977; Loskey \& Sarosi, 1978). A few cases have been described com- $\stackrel{\varnothing}{\complement}$ plicating the course of gram negative pneumonias.. especially with Pseudomonas (Unger et al., 1973; Zornoza et al., 1976). Small cavities are not unusual radiological findings during the course of Proteus pneumonia, thus reflecting the necrotizing effect of this organism; however definite pneumatoceles are extremely rare. Unger et al. (1973) found that 6 of 8 patients with Proteus pneumonia developed cavita- os tions, of which five were smaller than $1 \mathrm{~cm}$, and one $\vec{\circ}$ smaller than $3 \mathrm{~cm}$. Zornoza et al. (1976) and Tillostone \& Lerner $(1966 a, b)$ found only small cavities in $\vec{\omega}$ patients with Proteus pneumonia. Our patient presented initially with a single pneumatocele which rapidly enlarged. Multiple large pneumatoceles then developed which occupied most of the volume of the left hemithorax. There was no correlation between the radiographic findings which showed progression of the cavities and the clinical symptoms which im- of proved. Complete recovery and resolution of the pneumatoceles were noted. The excellent outcome and resolution of post-pneumonic pneumatocele in otherwise normal, healthy children and adults was mentioned by other authors (Victoria et al., 1981; Robbins \& Arora, 1981).

In conclusion we have presented an unusual case ơ adult with Proteus mirabilis pneumonia complicated by large multiple pneumatoceles. This complication does not appear to imply a bad prognosis and does not require therapy, other than for the underlying pneumonia.

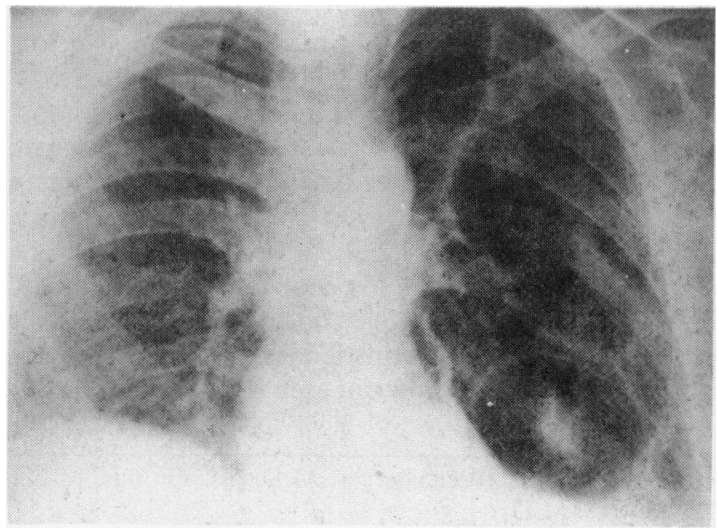

Figure 4 Chest X-ray on discharge demonstrates reabsorption of the intracavitary fluid and partial resolution of the pneumatoceles. 


\section{References}

BOISSET, G.F. (1972). Subpleural emphysema complicating staphylococcal and other pneumonias. Journal of Pediatrics, 18, 259.

FRASER, R.G. \& PARÉ, J.A.P. (1979). Bullous disease of the lungs. In: Diagnosis of Diseases of the Chest, Vol.3, p. 1421. W.B. Saunders, Philadelphia.

LOSKEY, W. \& SAROSI, G.A. (1978). The radiological appearance of pulmonary blastomycosis. Radiology, 126, 351.

LUDDY, R.E. (1977). Pneumocystis carini pneumonia with pneumatocele formation. American Journal of Diseases of Children, 131, 470.

ROBBINS, R.W.\& ARORA, N.S. (1981). Pulmonary cavitation caused by haemophilus influenza in adults. Southern Medical Journal, 74, 225.
TILLOSTONE, J.R. \& LERNER, A.M. (1966a). Characteristics of pneumonias caused by bacillus proteus. Annals of Internal Medicine, 68, 287.

TILLOSTONE, J.R. \& LERNER, A.M. (1966b). Pneumonias caused by gram-negative bacilli. Medicine, 45, 65 .

UNGER, D.J., ROSE, D.H. \& UNGER, F.G. (1973). Gram negative pneumonia. Radiology, 107, 283.

VALDIVIESO, M. (1977). Gram-negative pneumonia in the compromised host. Medicine, 56, 241.

VICTORIA, M.S., STEINER, P. \& RAO, M. (1981). Persistent postpneumonic pneumatoceles in children. Chest, 79, 359.

ZORNOZA, J., GOLDMAN, M.A., WALLACE, S., VALDIVIESO, M. \& BODEY, P.G. (1976). Radiologic features of gram-negative pneumonias in the neutropenic patient. American Journal of Roentgenology, 127, 989. 